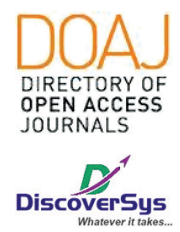

Published by DiscoverSys

\section{Pengaruh kombinasi Surface Pre-Treatment dan waktu inisiasi penyinaran terhadap kebocoran Mikro Restorasi RMGIC di RSGM Provinsi Sumatera Selatan}

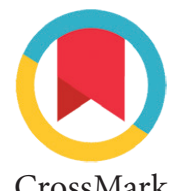

CrossMark

\author{
Aisyah Humairah, ${ }^{1 *}$ Rinda Yulianti, ${ }^{2}$ Martha Mozartha ${ }^{1}$
}

ABSTRACT

Background: Microleakage of RMGIC may occur due to smear layer interfere with the adhesion mechanism. Surface pretreatment to remove smear layer has been suggested. This study aims to evaluate the effect of combination surface pretreatment (dentin conditioner and acid-etch) and delayed light initiation on microleakage RMGIC restoration.

Methods: Class V cavities were prepared on 32 maxillary premolars which have fulfilled inclusion criteria and randomly divided into 4 groups. Cavities were pretreated with dentin conditioner (groupland II) and acid-etch (groups III and IV). All cavities were restored with RMGIC and immediate light initiation (group I and III), delayed light initiation for 3 minutes (group II and IV). All specimens were thermo-cycled

and immersed in Rhodamine-B $2 \%$ dye solution for 24 hours at $37^{\circ} \mathrm{C}$. Specimens were sectioned parallel to the axis of the tooth and the extent of Rhodamine-B dye penetration was examined under a USB Digital Microscope.

Results: Statistical analysis revealed significant differences between time initiation group ( 3 minutes and 0 minutes) $(P<0.05)$. T-test results showed a significant difference between groups I and IV and Group III and IV $(\mathrm{P}<0.05)$.

Conclusion: This study showed that there is no effect of the combined surface pretreatment and delayed light initiation on microleakage RMGIC restoration
\end{abstract}

${ }^{1}$ Program Studi Kedokteran Gigi, Fakultas Kedokteran Universitas Sriwijaya, Inderalaya Sumatera Selatan, Indonesia

${ }^{2}$ Dokter Gigi, RSKGM Provinsi Sumatera Selatan, Palembang, Indonesia

\footnotetext{
${ }^{*}$ Korespondensi: Martha Mozartha, Fakultas Kedokteran Universitas Sriwijaya, Inderalaya Sumatera Selatan, Indonesia; JL. Dr. Moh. Ali Komp. RSMH - Palembang; Kode Pos: 30126; Telepon: 0711-373438; martha.mozartha@gmail.com
}

Diterima: 2018-05-19 Disetujui: 2018-07-5 Diterbitkan: 2018-08-1

Keywords: Etch, dentin conditioner, light initiation, microleakage, RMGIC, surface pretreatment

Cite This Article: Humairah, A., Yulianti, R., Mozartha, M. 2018. Pengaruh kombinasi Surface Pre-Treatment dan waktu inisiasi penyinaran terhadap kebocoran Mikro Restorasi RMGIC di RSGM Provinsi Sumatera Selatan. Intisari Sains Medis 9(2): 160-164. D0I: 10.1556/ism.v9i2.271

\title{
ABSTRAK
}

Latar Belakang: Smear layer dapat mengganggu proses adhesi bahan restorasi RMGIC ke jaringan gigi dan mengakibatkan kebocoran mikro. Penghilangan smear layer dapat dilakukan dengan aplikasi bahan surface pretreatment. Penelitian bertujuan mengevaluasi pengaruh kombinasi bahan surface pretreatment (dentin conditioner dan etsa) dan penundaan waktu inisiasi penyinaran terhadap kebocoran mikro restorasi RMGIC.

Medote: Sebanyak 32 gigi premolar rahang atas yang telah memenuhi kriteria inklusi dipreparasi kavitas kelas V dan dibagi secara acak menjadi 4 kelompok. Kelompok I dan II diaplikasikan bahan surface pretreatment pada kavitas menggunakan dentin conditioner, sementara kelompok III dan IV menggunakan etsa. Gigi direstorasi menggunakan RMGIC dan dilakukan inisiasi penyinaran langsung (kelompok I dan III) atau penundaan waktu inisiasi selama 3 menit (kelompok II dan IV). Seluruh sampel melalui proses thermocycling dan direndam dalam larutan Rhodamine-B 2\% selama 24 jam pada suhu $37^{\circ}$ C. Sampel dipotong sejajar sumbu gigi dan diukur kedalaman penetrasi pewarnaan Rhodamine-B dengan USB Digital Microscope. Hasil: Hasil uji statistik menunjukkan bahwa terdapat perbedaan yang signifikan antar kelompok waktu inisiasi (3 menit dan 0 menit) $(\mathrm{P}<0.05)$. Hasil uji-T menunjukkan perbedaan kebocoran mikro yang signifikan antar kelompok I dan IV serta kelompok III dan IV $(\mathrm{P}<0.05)$. Kesimpulan: Penelitian ini menunjukkan tidak ada pengaruh kombinasi surface pretreatment dan penundaan waktu inisiasi penyinaran terhadap kebocoran mikro restorasi RMGIC.

Kata kunci: Etsa, dentin conditioner, inisiasi penyinaran, kebocoran mikro, RMGIC, surface pretreatment, Cite Pasal Ini: Humairah, A., Yulianti, R., Mozartha, M. 2018. Pengaruh kombinasi Surface Pre-Treatment dan waktu inisiasi penyinaran terhadap kebocoran Mikro Restorasi RMGIC di RSGM Provinsi Sumatera Selatan. Intisari Sains Medis 9(2): 160-164. D0I: 10.1556/ism.v9i2.271

\section{PENDAHULUAN}

Karies merupakan proses demineralisasi yang disebabkan mikroorganisme dimana dapat berujung pada terbentuknya lubang atau kavitas Lokasi kavitas kelas $\mathrm{V}$ yang berada di servikal menyebabkan kelembaban sulit dikontrol, sehingga dibutuhkan pemilihan bahan restorasi yang tepat agar menghasilkan restorasi yang tahan lama. ${ }^{2}$ Kavitas kelas $\mathrm{V}$ dengan perluasan di bawah cemento-enamel junction (CEJ) tanpa awdanya perbatasan dengan email dapat menyebabkan peningkatan kebocoran mikro apabila menggunakan restorasi resin komposit Kebocoran mikro dapat menyebabkan 
terjadinya hipersensitivitas pada gigi pasca operasi, diskolorasi, dan karies sekunder. ${ }^{3}$

Alternatif bahan restorasi estetik yang sering digunakan pada kavitas kelas $\mathrm{V}$ antara lain Glass Ionomer Cement (GIC), Resin-Modified Glass Ionomer Cement (RMGIC) dan kompomer. ${ }^{4}$ RMGIC diperkenalkan sebagai alternatif resin komposit dengan perpaduan sifat GIC dan resin komposit. ${ }^{3}$ Layaknya GIC, RMGIC dapat melepaskan fluoride dan memiliki daya self-adhere terhadap struktur gigi. ${ }^{5}$

Daya self-adhere dihasilkan dari ikatan kimia antara gugus karboksil yang berasal dari cairan RMGIC dengan ion kalsium dari struktur gigi. Senyawa 2-hydroxyethyl methacrylate (HEMA) yang terkandung pada RMGIC akan berpenetrasi ke struktur gigi dan menciptakan retensi mikromekanik. ${ }^{6}$ Ikatan mikromekanik ini sangat tergantung pada kekasaran permukaan gigi dan kedalaman penetrasi RMGIC pada struktur gigi. Pada saat proses preparasi gigi, debris preparasi struktur gigi yang disebut sebagai smear layer dapat menutupi tubuli dentin. Smear layer dapat menyebabkan terbatasnya ikatan mikromekanik antara restorasi RMGIC dengan struktur gigi, untuk mencegahnya dibutuhkan proses penghilangan smear layer. ${ }^{7}$

Penghilangan smear layer dapat dilakukan dengan cara mengaplikasikan bahan berupa asam poliakrilat, asam fosfat, hidrogen peroksida, asam maleat, asam sitrat dan EDTA. ${ }^{3}$ Asam fosfat dapat menghilangkan smear layer sampai kedalaman 2-5 $\mu \mathrm{m}$, sedangkan asam poliakrilat hanya dapat menghilangkan smear layer dengan kedalaman $0,5 \mu \mathrm{m} .{ }^{7}$ Teori menyatakan semakin baik kemampuan suatu bahan dalam menghilangkan smear layer, maka semakin baik ikatannya dengan struktur gigi. Namun, dalam penelitiannya Bayrak dkk. mengungkapkan restorasi RMGIC yang dilakukan surface pretreatment dengan asam poliakrilat menghasilkan kebocoran mikro yang lebih rendah dibandingkan dengan asam fosfat, meskipun tidak signifikan. ${ }^{6}$ Mauro dkk. menyatakan bahwa surface pretreatment pada restorasi RMGIC menggunakan asam poliakrilat menghasilkan kekuatan ikatan yang lebih baik dibandingkan menggunakan asam fosfat. ${ }^{8}$

Penelitian yang dilakukan Shafei et al. menggabungkan proses surface pretreament dan penundaan waktu inisiasi penyinaran. Kombinasi keduanya dapat meningkatkan ikatan ion antara struktur gigi dan restorasi RMGIC. Pada penelitian tersebut Shafei dkk menggunakan asam poliakrilat sebagai bahan surface pretreatment dikombinasikan dengan penundaan waktu inisiasi penyinaran, secara signifikan menghasilkan penurunan kebocoran mikro dibandingkan dengan tanpa penundaan waktu inisiasi penyinaran. ${ }^{9}$ Namun, belum ada penelitian tentang kombinasi asam fosfat dan penundaan waktu inisiasi penyinaran. Penelitian ini dilakukan untuk mengetahui pengaruh kombinasi waktu inisiasi penyinaran dengan penggunaan bahan surface pretreatment yaitu dentin conditioner dan etsa dalam mengurangi kebocoran mikro pada restorasi RMGIC.

\section{BAHAN DAN METODE}

Penelitian ini menggunakan metode penelitian eksperimen laboratorik semu, dengan subjek penelitian yaitu gigi premolar rahang atas yang telah diekstraksi. Adapun kriteria inklusi gigi premolar yang digunakan dalam penelitian adalah sebagai berikut: bebas karies; tidak ada fraktur; foramen apikal telah menutup sempurna; tidak ada restorasi.

Sampel penelitian yang telah memenuhi kriteria inklusi dipreparasi kelas V G.V. Black pada bagian bukal yang sesuai dengan outline yang nantinya akan direstorasi menggunakan Resin Modified Glass Ionomer Cement (RMGIC) (Fuji II LC). Seluruh sampel dibagi menjadi 4 kelompok perlakuan, masing-masing terdiri dari 8 sampel (total $=32$ sampel).

Sebelum direstorasi dengan RMGIC, seluruh sampel diberi surface pretreatment. Sampel pada kelompok I dan II diaplikasikan dentin conditioner (GC Cavity Conditioner) selama 10 detik menggunakan microbrush, dibilas dengan air selama 15 detik, lalu dikeringkan. Sementara itu sampel gigi pada kelompok III dan IV diaplikasikan etsa menggunakan asam fosfat $37 \%$ (3M ESPE Scotchbond Etching Liquid) selama 15 detik, dibilas dengan air selama 15 detik dan dikeringkan. Selanjutnya, bahan restorasi RMGIC dimasukkan ke dalam kavitas. Pada kelompok I dan III dilakukan inisiasi penyinaran langsung dengan light curing unit selama 20 detik. Sedangkan pada kelompok II dan IV dilakukan penundaan selama 3 menit sebelum dilakukan penyinarandengan lightcuringunitselama 20 detik. Penyinaran dilakukan dengan cara melapisi celluloid strip pada permukaan restorasi. Setelah itu dilakukan prosedur finishing dan polishing dengan cawan aluminium oksida, kemudian semua sampel penelitian direndam di dalam cairan aquades menggunakan tabung mika dan disimpan di inkubator dengan suhu 370C selama 24 jam.

Selanjutnya dilakukan proses thermocycling pada sampel secara manual sebanyak 100 kali pada suhu $50 \mathrm{C}$ dan $550 \mathrm{C}$ dengan waktu perendaman dalam setiap suhu selama 20 detik dan waktu transfer selama 10 detik. ${ }^{10}$ Kemudian, ujung akar gigi ditutup dengan menggunakan sticky wax untuk menghindari zat warna berpenetrasi melalui area ujung akar. Seluruh permukaan gigi dilapisi dengan cat kuku kecuali area $1 \mathrm{~mm}$ dari tepi restorasi. Sampel 
Tabel 1 Hasil Uji Two-Way ANOVA

\begin{tabular}{lc}
\hline Variabel & Nilai P \\
\hline Waktu & $0,013^{\star}$ \\
Bahan Surface Pretreatment & 0,220 \\
Waktu ${ }^{*}$ Bahan Surface Pretreatment & 0,596 \\
\hline
\end{tabular}

Keterangan: tanda $\left({ }^{*}\right)$ menunjukan signifikansi $(\mathrm{p}<0,05)$

Tabel 2 Analisis uji T perbandingan kebocoran mikro antarkelompok perlakuan

\begin{tabular}{llccc}
\hline Kelompok & I & II & III & IV \\
\hline I & - & 0,214 & 0,689 & $0,025^{*}$ \\
II & - & - & 0,335 & 0,091 \\
III & - & - & - & $0,016^{*}$ \\
IV & - & - & - & - \\
\hline
\end{tabular}

Keterangan: tanda $\left(^{*}\right)$ menunjukan signifikansi $(\mathrm{p}<0,05)$

\section{- Kelompok I Kelompok II Kelompok III $\quad$ Kelompok IV}

\section{$0,708 \pm 0,561 \mathrm{~mm}$}

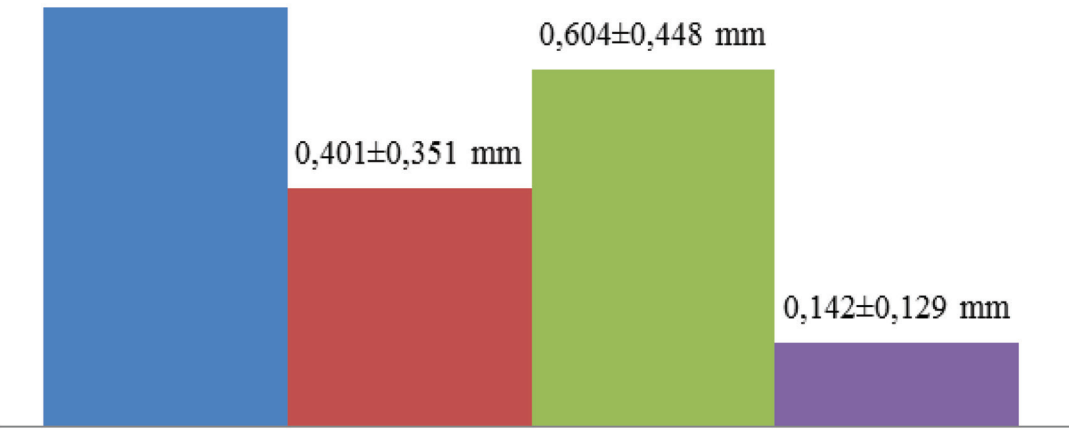

Gambar 2 Diagram nilai rerata \pm SD kebocoran mikro restorasi kelas V RMGIC menggunakan kombinasi bahan surface pretreatment dan waktu inisiasi penyinaran

kemudian direndam dalam larutan rhodamine- $B$ $2 \%$ selama 24 jam di dalam tabung mika. Setelah itu gigi dibersihkan menggunakan cairan aquades dan dikeringkan, kemudian dilanjutkan dengan pengukuran kebocoran mikro.

Sampel dipotong menggunakan diamond separating disc secara longitudinal pada pertengahan restorasi sejajar sumbu panjang gigi dan tegak lurus bidang oklusal dari permukaan bukal ke lingual yang memisahkan mesial dan distal. Pengukuran kebocoran mikro dilakukan dengan melihat kedalaman penetrasi pewarnaan menggunakan mikroskop pada pembesaran 100 kali. Hasil pengukuran kedalaman penetrasi rhodamine- $B$ pada tepi restorasi dalam satuan milimeter $(\mathrm{mm})$ pada daerah margin gingiva pewarnaan ditulis dalam tabel, dilanjutkan dengan analisa statistik.

\section{HASIL}

Penelitian eksperimental mengenai pengaruh kombinasi surface pretreatment dan penundaan waktu inisiasi penyinaran terhadap kebocoran mikro restorasi kelas V RMGIC telah dilakukan di Rumah Sakit Khusus Gigi dan Mulut Provinsi Sumatera Selatan dan Laboratorium Biokimia Fakultas Kedokteran Universitas Sriwijaya Madang pada bulan Februari 2017.

Sampel dibagi menjadi 4 kelompok perlakuan yaitu, I (surface pretreatment dentin conditioner dan inisiasi penyinaran langsung), II (surface pretreatment dentin conditioner dan penundaan inisiasi penyinaran selama 3 menit), III (surface pretreatment etsa dan inisiasi penyinaran langsung), IV (surface pretreatment etsa dan penundaan inisiasi penyinaran selama 3 menit). Kebocoran mikro restorasi kelas V RMGIC diukur menggunakan jangka sorong dengan cara melihat kedalaman penetrasi zat pewarna pada margin gingiva menggunakan USB Digital Microscope.

Hasil rerata pengukuran kedalaman kebocoran mikro restorasi kelas V RMGIC dapat dilihat pada Gambar 1.

Nilai rerata kebocoran mikro yang lebih rendah terdapat pada kelompok restorasi RMGIC yang menggunakan bahan surface pretreatment etsa jika dibandingkan dengan menggunakan dentin conditioner. Hasil rerata kebocoran mikro yang lebih rendah juga terlihat pada kelompok yang mendapatkan perlakuan penundaan inisiasi penyinaran selama 3 menit dibandingkan dengan kelompok yang tidak dilakukan penundaan penyinaran. Selanjutnya data dianalisis secara statistik dengan uji parametrik yaitu uji two-way ANOVA, hasilnya ditampilkan pada Tabel 1.

Tabel 1 menunjukkan angka probabilitas sebesar $\mathrm{P}<0,05$ hanya pada waktu inisiasi penyinaran. Hal ini berarti hipotesis satu ditolak, yaitu tidak ada pengaruh kombinasi surface pretreatment dan penundaan waktu inisiasi penyinaran terhadap kebocoran mikro kelas V RMGIC. Kemudian dilakukan uji $\mathrm{T}$ untuk mengetahui signifikansi perbedaan rerata antar kelompok perlakuan. Hasil uji T dapat dilihat pada Tabel 2 dimana menunjukkan terdapat perbedaan yang bermakna antara kelompok I dan IV dengan kelompok III dan IV $(\mathrm{P}<0.05)$

\section{PEMBAHASAN}

Kebocoran mikro disebabkan adaptasi bahan restorasi yang kurang baik terhadap struktur gigi. Kebocoran mikro dapat menyebabkan terjadinya 
karies sekunder, perubahan warna pada gigi, sensitivitas pasca perawatan dan iritasi pulpa. ${ }^{6}$

Hasil penelitian ini menunjukkan bahwa tidak satupun kelompok perlakuan yang bebas dari kebocoran mikro. Nilai kebocoran mikro tertinggi terdapat pada kelompok I, yaitu kelompok sampel yang diberi perlakuan dentin conditioner dan penyinaran langsung dilakukan setelah kavitas direstorasi dengan RMGIC. Kemudian disusul dengan kelompok III yaitu kelompok sampel dengan perlakuan etsa asam fosfat dan juga langsung dilakukan penyinaran setelah restorasi, namun kedua kelompok ini tidak berbeda secara signifikan. Hasil ini sejalan dengan penelitian sebelumnya yang dikemukakan oleh Bayrak et al. bahwa tidak ada perbedaan signifikan antar penggunaan surface pretreatment etsa dan dentin conditioner pada kebocoran mikro restorasi RMGIC. ${ }^{6}$

Terdapat dua mekanisme reaksi pengerasan pada bahan RMGIC, yang pertama adalah reaksi asam basa yang terjadi secara perlahan yang dimulai segera setelah manipulasi dan terus berlanjut hingga 24 jam atau bahkan 1 minggu. ${ }^{4}$ Yang kedua adalah reaksi polimerisasi yang terjadi lebih cepat, dan merupakan reaksi dari monomer yang teraktivasi oleh paparan sinar tampak. ${ }^{4}$ Dengan demikian, bahan RMGIC memperoleh retensi ke struktur jaringan keras gigi melalui dua cara yaitu melalui ikatan kimia antara asam poliakrilat dengan hidroksiapatit, serta ikatan mikromekanis melalui penetrasi komponen monomer resin ke permukaan dentin yang bebas smear layer dan telah terdemineralisasi sebagian. Ikatan kimiaRMGIC ke struktur gigi bergantung pada ketersediaan kalsium pada permukaan gigi.

Asam poliakrilat yang terkandung dalam dentin conditioner merupakan asam lemah yang mampu menghilangkan smear layer, sehingga semen dapat lebih mudah berpenetrasi ke dalam tubulus dentin yang terbuka. ${ }^{11}$ Sementara itu, asam fosfat dapat mengakibatkan demineralisasi yang lebih dalam, dimana konsentrasi kalsium lebih rendah daripada di lapisan superfisial. Tay dkk. melaporkan bahwa pengetsaan dengan asam fosfat $37 \%$ selama 15 detik menurunkan kekuatan ikatan bahan GIC karena hilangnya ion kalsium yang dibutuhkan untuk terjadinya ikatan GIC dan dentin. ${ }^{12}$ Namun pada penelitian ini tampak bahwa pengetsaan menggunakan asam fosfat menghasilkan kebocoran mikro lebih rendah dibanding kelompok yang menggunakan dentin conditioner. Hal ini kemungkinan dapat disebabkan karena bahan yang digunakan dalam penelitian ini adalah RMGIC yang mengandung resin, yang mana retensi ke struktur gigi tidak hanya bergantung pada ikatan kimia antara material dengan kalsium pada struktur gigi. Hamama dkk. dalam penelitiannya merekomendasikan pengurangan waktu aplikasi etsa asam fosfat menjadi 5 detik untuk meningkatkan infiltrasi komponen resin pada RMGIC ke dalam lapisan dentin yang terdemineralisasi. ${ }^{13}$

Hasil dari penelitian ini menunjukkan bahwa surface pretreatment dengan dentin conditioner maupun etsa asam fosfat menunjukkan kebocoran mikro yang lebih rendah jika penyinaran ditunda selama 3 menit, dibandingkan dengan penyinaran langsung. Hal ini sejalan dengan penelitian Shafiei dkk yang pada penelitiannya mendapatkan bahwa penundaan penyinaran pada permukaan yang telah diberi perlakuan menghasilkan marginal sealing yang lebih baik. Jika penyinaran langsung dilakukan, jaringan polimer yang bertautan silang segera terbentuk dan ini menyebabkan difusi dari reaktan asam basa menjadi terbatas. Penundaan penyinaran dapat memberi waktu yang lebih banyak bagi terjadinya ikatan ionik gugus karboksil pada asam poliakrilat dengan partikel kaca pada reaksi pengerasan RMGIC, serta terjadinya ikatan kimia dengan kalsium. ${ }^{9}$ Reaksi asam basa pada antarmuka RMGIC menjadi lebih sempurna, dan komponen resin diperkirakan memiliki waktu lebih untuk berpenetrasi ke dalam zona demineralisasi yang terbentuk dan menyebabkan ikatan mikromekanik antara restorasi RMGIC menjadi lebih baik. ${ }^{8}$ Ini dapat menjelaskan kebocoran mikro yang rendah pada kelompok dengan penundaan inisiasi penyinaran.

\section{KESIMPULAN}

Hasil penelitian ini menunjukkan bahwa tidak terdapat pengaruh kombinasi surface pretreatment dan penundaan waktu inisiasi penyinaran terhadap kebocoran mikro restorasi RMGIC. Nilai kebocoran mikro yang paling rendah diperoleh pada kelompok surface pretreament menggunakan etsa asam fosfat $37 \%$ selama 15 detik dimana memiliki penundaan waktu inisiasi penyinaran selama 3 menit.

\section{DAFTAR PUSTAKA}

1. Baum, Lloyd, Ralph W. Phillips, Melvin R. Lund. Buku Ajar Ilmu Konservasi Gigi Alihbahasa: Prof. Dr. drg. Rasinta Tarigan. Jakarta: EGC, 1997: 119-217.

2. Bayne SC, Thompson JY, Taylor DF. Dental materials. In : Roberson TM, Heyman HO, Swift EJ, eds. Sturdevant's Art and Science of Operative Dentistry. 4th ed. Missouri: Mosby, Inc.,2002: 177-91.

3. Gupta SK, Gupta J, Saraswathi V, Ballal V, Acharya SR. Comparative Evaluation of Microleakage In Class V 
Cavities Using Various Glass Ionomer Cements: An In Vitro Study. J Interdiscip dentistry 2012;2:164-9.

4. Bayne SC, Thompson JY, Taylor DF. Dental materials. In : Roberson TM, Heyman HO, Swift EJ, eds. Sturdevant's Art and Science of Operative Dentistry. 4th ed. Missouri: Mosby, Inc.,2002: 177-91.

5. Khoroushi M, Karvandi TM, Kamali B, Mazaheri H. Marginal Microleakage of Resin-Modified Glass-Ionomer and Composite Resin Restorations: Effect of Using EtchAnd-Rinse and Self-Etch Adhesives. Indian J Dent Res. 2012; 23(3):378-83

6. Bayrak S, Sen TE, Tuloglu N. The Effects of Surface Pretreatment on The Microleakage of Resin-Modified Glass-Ionomer Cement Restorations. The Journal of Clinical Pediatric Dentistry 36(3):279-284,2012.

7. Summit JB. Robbins JW. Hilton TJ. Schwartz RS. Santos J Jr. Fundamentals of Operative Dentistry: A Contemporary Approach 3rd edition. Illinois: Quintessence Publishing Co, Inc, 2006: 184-234.

8. Mauro SJ, Sundfelt RH, Bedran RAKB, Fraga BALF. Bond Strength of Resin-Modified glass Ionomer to Dentin: The Effect of Dentin Surface Treatment. J Minim Interv Dent 2009; 2 (1); 45-53.

9. Shafiei F, Yousefipour B, Farhadpour H. Marginal Microleakage of A Resin-Modified Glass-Ionomer
Restoration: Interaction Effect of Delayed Light Activation and Surface Pretreatment. Dent Res J (Isfahan). 2015; 12(3): 224-230.

10. Halim SE, Zaki D. Comparative Evaluation of Microlekage Among Three Different Glass Ionomer Types. Operative Dentistry, 2011, 36-1,36-42.

11. Wang L, Sakai VT, Kawai ES, Buzalaf MA, Atta MT. Effect of adhesive systems associated with resin-modified glass ionomer cements. J Oral Rehabil. 2006; 33(2):110-6.

12. Tay FR, Smales RJ, Ngo H, Wei SH, Pashley DH. Effect of different conditioning protocols on adhesion of a GIC to dentin. J Adhes Dent. 2001; 3(2):153-167

13. Hamama HH, Burrow, Yi C. Effect of dentine conditioning on adhesion of resin-modified glass ionomer adhesives. Australian Dental Journal 2014; 59(2): 193-200

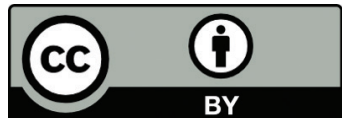

This work is licensed under a Creative Commons Attribution 